\title{
PENGARUH DUKUNGAN SUAMI DAN DUKUNGAN ATASAN TERHADAP KEBERHASILAN PEMBERIAN AIR SUSU IBU (ASI) EKSKLUSIF PADA IBU BEKERJA DI WILAYAH KERJA UPT BLUD PUSKESMAS TANJUNG KARANG TAHUN 2016
}

\author{
Yunita Marliana \\ Fakultas Kedokteran Universitas Islam Al-Azhar \\ J1. Unizar No.20 Turida Mataram
}

\begin{abstract}
ABSTRAK
World Health Organization (WHO) merekomendasikan pamberian ASI Eksklusif sekurang-kurangnya selama 6 bulan pertama kehidupan dan dilanjutkan dengan makanan pendamping sampai usia 2 tahun, rekomendasi serupa juga oleh American Academy of Pediatrics (AAP), Academy of Breasfeeding Medicine demikian pula oleh Ikatan Dokter Anak Indonesia (IDAI). Diperkirakan bahwa pemberian ASI eksklusif dapat mengurangi kematian bayi sebesar 13\%. Pemberian ASI eksklusif telah diakui sebagai salah satu intervensi utama di seluruh dunia utuk mengurangi angka kematian bayi dan anak-anak.

Penelitian ini menggunakan jenis observasional analitik dengan dan desain cross sectional. Lokasi penelitian dilakukan di Wilayah Kerja UPT BLUD Puskesmas Tanjung Karang pada bulan Mei-Juni 2016. Populasi dalam penelitian ini adalah semua ibu bekerja (sektor negeri maupun swasta) yang memiliki bayi yang berusia 7-12 bulan. Sampel yang digunakan adalah keseluruhan populasi atau Total Sampling, sebanyak 34 orang.

Berdasarkan hasil penelitian ditemukan Ibu bekerja yang mendapatkan dukungan dari suami sebagian besar berhasil menyusui bayinya sebanyak 76,5\%. Dengan hasil uji Chi Square 0,001 sehingga dapat disimpulkan ada pengaruh dukungan suami terhadap keberhasilan pemberian ASI Ekslusif pada ibu bekerja. Sedangkan mayoritas ibu bekerja yang mendapatkan dukungan dari atasannya memiliki tingkat keberhasilan pemberian ASI Ekslusif sebanyak 78,9\%. Dengan hasil uji Chi Square 0,000 sehingga dapat disimpulkan ada pengaruh dukungan atasan terhadap keberhasilan pemberian ASI Ekslusif pada ibu bekerja.
\end{abstract}

Kata Kunci: Dukungan, Keluarga, Atasan, ASI Ekslusif.

\section{LATAR BELAKANG}

Air Susu Ibu (ASI) merupakan nutrisi yang paling baik untuk perkembangan dan pertumbuhan bayi. World Health Organization (WHO) merekomendasikan pamberian ASI Eksklusif sekurang-kurangnya selama 6 bulan pertama kehidupan dan dilanjutkan dengan makanan pendamping sampai usia 2 tahun, rekomendasi serupa juga oleh American Academy of Pediatrics (AAP), Academy of Breasfeeding Medicine demikian pula oleh Ikatan Dokter Anak Indonesia (IDAI).
Diperkirakan bahwa pemberian ASI eksklusif dapat mengurangi kematian bayi sebesar 13\%. Pemberian ASI eksklusif telah diakui sebagai salah satu intervensi utama di seluruh dunia utuk mengurangi angka kematian bayi dan anak - anak. Salah satu bentuk perhatian pemerintah Indonesia terhadap pentingnya ASI Eksklusif adalah dengan dikeluarkannya Peraturan Pemerintah No. 33 tahun 2012 tentang Pemberian Air Susu Ibu Eksklusif, pasal 34 yang berbunyi "pengurus tempat kerja wajib memberikan kesempatan kepada ibu yang bekerja untuk memberikan ASI Eksklusif 
atau memerah ASI selama waktu kerja di tempat kerja".

Angka menyusui di dunia maupun di Indonesia sendiri masih sangat buruk. Pada Sidang Kesehatan Dunia ke-65, negara - negara anggota WHO menetapkan target di tahun 2025 bahwa sekurang - kurangnya 50\% dari jumlah bayi di bawah usia enam bulan diberi ASI Eksklusif. Ketika mengevaluasi praktik pemberian ASI eksklusif di 139 negara, UNICEF menyampaikan temuan bahwa hanya $20 \%$ dari negara-negara yang diteliti mempraktikkan pemberian ASI ekslusif pada lebih dari 50\% bayi yang ada. Selebihnya, $80 \%$ dari negara-negara tersebut melakukan pemberian jauh lebih rendah dari $50 \%$.

Pemerintah menargetkan cakupan pemberian ASI eksklusif sebesar 80\%, namun target ini belum tercapai. Berdasarkan data Riskesdas tahun 2013, hanya 30,2\% bayi usia 6 bulan yang diberi ASI saja dalam 24 jam terakhir dan tidak diberi makanan pralakteal. Rendahnya cakupan pemberian ASI eksklusif menunjukkan bahwa tidak banyak ibu yang berhasil memberikan ASI eksklusif.

ASI memiliki banyak manfaat kesehatan bagi ibu dan bayi. ASI mengandung semua nutrisi bayi kebutuhan dalam 6 bulan pertama kehidupan. Ini adalah yang paling ideal, aman, dan lengkap makanan yang ibu dapat memberikan untuk yang baru lahir.

Oleh karena itu, WHO merekomendasikan bayi harus ASI eksklusif selama 6 bulan pertama kehidupan untuk mencapai pertumbuhan dan kesehatan yang optimal.

Beberapa penelitian menyebutkan bahwa status pekerjaan ibu sebagai salah satu penghambat pemberian ASI eksklusif. Penelitian di Vietnam menunjukkan bahwa ibu yang bekerja memiliki risiko 14 kali lebih besar tidak memberikan ASI eksklusif. Penelitian yang dilakukan di Jakarta menunjukkan hanya $32 \%$ perempuan pekerja sector formal dan $20 \%$ perempuan pekerja sektor industry yang memberikan ASI eksklusif.

Bagi ibu bekerja memberikan ASI eksklusif bukan hal mudah. Ibu bekerja perlu memiliki sikap positif, pengetahuan, keterampilan, komitmen diri, komunikasi yang terbuka, serta dukungan sosial dan tempat bekerja agar berhasil memberikan ASI eksklusif. Faktor-faktor yang menyebabkan kegagalan pemberian ASI eksklusif pada ibu bekerja antara lain adanya persepsi bahwa ASI tidak cukup, kurangnya pengetahuan manajemen laktasi saat bekerja, kurangnya waktu untuk memerah ASI, fasilitas yang tidak kondusif untuk menyusui atau memerah ASI, dan tidak ada dukungan dari pimpinan. 
Kesuksesan dan keberhasilan menyusui, sangat dipengaruhi oleh kesiapan ibu sendiri baik secara fisik maupun mentalnya untuk menyusui. Secara hipotetik kesiapan ibu sendiri baik untuk melahirkan dan menyusui sangat dipengaruhi oleh pengetahuan ibu perihal manfaat ASI. Pengetahuan ibu yang semakin baik, diestimasi ibu akan lebih siap menyusui. Seorang ayah juga mempunyai peran yang sangat penting dalam keberhasilan ibu menyusui, terutama untuk menjaga agar refleks oksitosin lancar, ayah dapat berperan aktif dalam keberhasilan pemberian ASI dengan jalan memberikan dukungan secara emosional dan dukungandukungan praktis lainnya. Jadi keberhasilan menyusui seorang ibu tidak hanya tergantung pada sang ibu sendiri, tetapi juga pada ayah si bayi.

Berdasarkan data Dinas Kesehatan Provinsi Nusa Tenggara Barat (NTB) tahun 2014, cakupan ASI Eksklusif mencapai $71,95 \%$. Cakupan ASI Eksklusif di tertinggi sekota Mataram adalah Puskesmas Tanjung Karang mencapai $72,05 \%$.

Adapun faktor yang mempengaruhi cakupan ASI Eksklusif salah satunya adalah pekerjaan ibu. Dewasa ini jumlah perempuan yang bekerja terus meningkat. Hal ini merupakan salah satu faktor ibu tidak memberikan ASI Eksklusif dengan berbagai alasan di antaranya rasa malas, beban bekerja, cuti yang kurang, sarana prasarana yang terbatas dan tututan ekonomi. Faktor lain yang mempengaruhi pemberian ASI eksklusif pada ibu bekerja juga tak lepas dari dukungan keluarga dan dukungan sosial dari rekan kerja maupun atasan.

\section{METODE PENELITIAN}

Penelitian ini menggunakan jenis observasional analitik dengan dan desain cross sectional. Lokasi penelitian dilakukan di seluruh wilayah kerja UPT BLUD Puskesmas Tanjung Karang pada bulan Mei-Juni 2016. Populasi dalam penelitian ini adalah semua ibu bekerja (sektor negeri maupun swasta) yang memiliki bayi yang berusia 7-12 bulan. Sampel yang digunakan adalah keseluruhan populasi atau Total Sampling, sebanyak 34 orang.

\section{HASIL}

Pekerjaan ibu dalam penelitian ini bervariasi antara lain: 1) karyawan swasta yang terdiri dari: sales promotion girl (SPG), karyawan bank dan bandara , 2) guru honorer dan 3) PNS. Dengan jam kerja berkisar antara 7-10 jam. Sebagian besar ibu kembali bekerja sebelum bayinya berusia 6 bulan. Karakteristik subjek penelitian dapat dilihat pada tabel berikut ini.
Tabel 1. Karakteristik ibu bekerja yangmemberikan ASI ekslusif.




\begin{tabular}{|c|c|c|c|}
\hline \multicolumn{2}{|c|}{ Karakteristik } & \multirow[b]{2}{*}{32} & \multirow{2}{*}{$\begin{array}{r}\% \\
94,1\end{array}$} \\
\hline Umur & $\begin{array}{c}20-35 \\
\text { tahun }\end{array}$ & & \\
\hline & $>35$ tahun & 2 & 5,9 \\
\hline \multirow[t]{2}{*}{ Pendidikan } & Menengah & 9 & 26,5 \\
\hline & Tinggi & 25 & 73,5 \\
\hline \multirow[t]{3}{*}{ Pekerjaan } & PNS & 7 & 20,6 \\
\hline & $\begin{array}{c}\text { Karyawan } \\
\text { Swasta }\end{array}$ & 17 & 50,0 \\
\hline & $\begin{array}{c}\text { Guru } \\
\text { Honorer }\end{array}$ & 10 & 29,4 \\
\hline \multirow[t]{3}{*}{ Paritas } & Primipara & 16 & 47,1 \\
\hline & Multipara & 17 & 50,0 \\
\hline & $\begin{array}{l}\text { Grandemul } \\
\text { tipara }\end{array}$ & 1 & 2,9 \\
\hline \multirow[t]{2}{*}{ Jam Kerja } & 7-8 jam & 31 & 91,2 \\
\hline & $>8 \mathrm{jam}$ & 3 & 8,8 \\
\hline
\end{tabular}

Berdasarkan tabel diatas dapat dilihat karakteristik sebagian besar subjek penelitian berusia 20 - 35 tahun sebanyak $94,1 \%$, pendidikan tinggi sebanyak $73,5 \%$, pekerjaan sebagai karyawan swasta sebanyak 50,0\%, paritas multipara sebanyak 50,0\% dan memiliki jam kerja 7 -8 jam sehari sebanyak $91,2 \%$.

Kesibukan akibat bekerja diluar rumah menghambat ibu untuk menyusui bayinya dengan baik di tambah dengan terbatasnya waktu cuti hamil dan melahirkan bagi ibu-ibu bekerja menyebabkan masa pemberian ASI ekslusif tidak dapat berlangsung lama karena ibu harus kembali bekerja. Hal ini mengakibatkan terhambatnya upaya untuk memberikan ASI secara ekslusif.

\section{DUKUNGAN SUAMI}

Menurut Roesli, 2005 dari semua dukungan bagi ibu menyusui dukungan sang ayah adalah dukungan yang paling berarti bagi ibu. Ayah dapat berperan aktif dalam keberhasilan pemberian ASI khususnya ASI eksklusif dengan cara memberikan dukungan secara emosional dan bantuan-bantuan yang praktis. Untuk membesarkan seorang bayi, masih banyak yang dibutuhkan selain menyusui seperti menyendawakan bayi, menggendong dan menenangkan bayi yang gelisah, mengganti popok, memandikan bayi, membawa bayi jalan-jalan di taman, memberikan ASI perah, dan memijat bayi. Kecuali menyusui semua tugas tadi dapat dikerjakan oleh ayah. Dukungan suami dapat dilihat pada tabel dibawah ini.

Tabel 2. Dukungan Suami Terhadap Keberhasilan ASI Ekslusif Pada Ibu Bekerja

\begin{tabular}{ccccc}
\multicolumn{5}{c}{ Pada Ibu Bekerja } \\
\cline { 1 - 3 } $\begin{array}{c}\text { Dukunga } \\
\text { n Suami }\end{array}$ & $\begin{array}{c}\text { Tidak Ekslusif } \\
\text { Berha } \\
\text { sil }\end{array}$ & $\begin{array}{c}\text { Berha } \\
\text { sil }\end{array}$ & & $\begin{array}{c}\text { Nil } \\
\text { ai p }\end{array}$ \\
\hline Tidak & 14 & 3 & 17 & \\
& $\begin{array}{c}82,4 \\
\%\end{array}$ & $\begin{array}{c}17,6 \\
\%\end{array}$ & 50 & \\
& $\%$ & $\%$ & \\
Menduk & 4 & 13 & 17 & 0,0 \\
ung & 23,5 & 76,5 & 50 & \\
& $\%$ & $\%$ & $\%$ & \\
Total & 18 & 16 & 34 & \\
& 52,9 & 47,1 & 100 & \\
& $\%$ & $\%$ & $\%$ & \\
\hline
\end{tabular}

Berdasarkan data diatas dapat dilihat bahwa ibu bekerja yang mendapatkan dukungan dari suami sebagian besar berhasil menyusui bayinya sebanyak $76,5 \%$. Dengan hasil uji Chi 
Square 0,001 sehingga dapat disimpulkan ada pengaruh dukungan suami terhadap keberhasilan pemberian ASI Ekslusif pada ibu bekerja.

Seorang ayah juga mempunyai peran yang sangat penting dalam keberhasilan ibu menyusui, terutama untuk menjaga agar refleks oksitosin lancar, ayah dapat berperan aktif dalam keberhasilan pemberian ASI dengan jalan memberikan dukungan secara emosional dan dukungan-dukungan praktis lainnya. Jadi keberhasilan menyusui seorang ibu tidak hanya tergantung pada sang ibu sendiri, tetapi juga pada ayah si bayi.

Dukungan ayah sangat penting dalam suksesnya menyusui, terutama untuk ASI eksklusif. Dukungan emosional suami sangat berarti dalam menghadapi tekanan luar yang meragukan perlunya ASI. Ayahlah yang menjadi benteng pertama saat ibu mendapat godaan yang datang dari keluarga terdekat, orangtua atau mertua. Ayah juga harus berperan dalam pemeriksaan kehamilan, menyediakan makanan bergizi untuk ibu dan membantu meringankan pekerjaan istri. Kondisi ibu yang sehat dan suasana yang menyenangkan akan meningkatkan kestabilan fisik ibu sehingga produksi ASI lebih baik. Lebih lanjut ayah juga ingin berdekatan dengan bayinya dan berpartisipasi dalam perawatan bayinya, walau waktu yang dimilikinya terbatas. Ayah yang berperan mendukung ibu agar menyusui sering disebut breastfeeding father.

Kurangnya dukungan keluarga terutama dari suami merupakan faktor yang sering dijumpai, pemberian makanan prelaktal terlalu dini yang merupakan kebiasaan dari keluarga menjadi faktor penghambat untuk memberikan ASI, serta kurangnya perhatian suami terhadap asupan gizi ibu menyusui. Suami merupakan pendukung terbaik bagi ibu muda yang menyusui. Bila suami bersedia, ia dapat menolong istri dalam hal ini. Suami dapat memberitahu istrinya bahwa ia ingin istrinya menyusui dan mengatakan bahwa ASI merupakan makanan terbaik bagi bayi.

Ayah dapat berperan aktif dalam keberhasilan pemberian ASI dengan jalan memberikan dukungan secara emosional dan bantuan- bantuan praktis lainnya, seperti popok atau menyendawakan bayi. Pengertian tentang perannya yang penting ini merupakan langkah pertama bagi seorang ayah untuk dapat mendukung ibu agar berhasil menyusui secara eksklusif.

\section{DUKUNGAN ATASAN}

Tabel 3. Dukungan Atasan Terhadap Keberhasilan ASI Ekslusif Pada Ibu Bekerja

\begin{tabular}{ccccc}
\multicolumn{4}{c}{ Pada Ibu Bekerja } \\
\hline \multirow{3}{*}{ Dukun } & ASI Ekslusif & & \\
\cline { 2 - 2 } gan & Tidak & Berh & $\%$ & Nil \\
Atasan & $\begin{array}{c}\text { Berha } \\
\text { sil }\end{array}$ & asil & & ai p \\
\hline
\end{tabular}




\begin{tabular}{ccccc}
\hline Tidak & 14 & 1 & 15 & \\
& $93,3 \%$ & $6,7 \%$ & $\begin{array}{c}44,12 \\
\%\end{array}$ & \\
& & & 15 & 0,0 \\
$\begin{array}{c}\text { Mendu } \\
\text { kung }\end{array}$ & 4 & 15 & 19 & 00 \\
& $21,1 \%$ & $\begin{array}{c}78,9 \\
\%\end{array}$ & $\begin{array}{c}55,88 \\
\%\end{array}$ & \\
Total & 18 & 16 & 34 & \\
& & $\begin{array}{c}47,1 \\
\%\end{array}$ & $\begin{array}{c}100 \\
\%\end{array}$ & \\
& $52,9 \%$ & & \\
\hline
\end{tabular}

Berdasarkan tabel diatas dapat dilihat bahwa sebagian besar ibu bekerja yang mendapatkan dukungan dari atasannya memiliki tingkat keberhasilan pemberian ASI Ekslusif sebanyak 78,9\%. Dengan hasil uji Chi Square 0,000 sehingga dapat disimpulkan ada pengaruh dukungan atasan terhadap keberhasilan pemberian ASI Ekslusif pada ibu bekerja.

Dalam penelitian ini didapatkan bentuk dukungan atasan antara lain dengan pemberian cuti, untuk responden yang bekerja di sektor negeri rata-rata mendapatkan cuti 3 bulan, cuti yang diberikan biasa 1 bulan sebelum melahirkan dan 2 bulan setelah melahirkan. Untuk bekerja di sektor swasta pemberian cuti berkisar antar 1-3 bulan, cuti yang diberikan sebaian besar sama seperti di sektor negeri.

Selain pemberian cuti, bentuk dukungan atasan yang diberikan adalah waktu istirahat dan izin pulang untuk menyusui bayi. Sebagian besar atasan tempat subjek penelitian bekerja baik negeri maupun swasta memberikan dukungan tersebut asal tidak mengganggu pekerjaan. Rata-rata waktu yang diberikan untuk istirahat atau pulang untuk memerah ASI dan menyusui bayi berkisar antara 1 - 2 jam. Namun terdapat pula tempat kerja swasta yang tidak menyediakan waktu baik untuk memerah maupun izin pulang untuk menyusui bayi. Dalam penelitian ini juga didapatkan sebagian besar tempat kerja tidak menyediakan fasilitas seperti ruangan khusus untuk memerah ASI, dan juga sebagian besar atasan tempat kerja tidak memperbolehkan untuk membawa bayi terutama di bidang swasta. Dukungan dari atasan sangat diperlukan dalam menentukan keberhasilan ASI eksklusif pada ibu yang bekerja. Dukungan atasan atau rekan kerja merupakan hal yang sangat penting dalam penentuan keberhasilan ASI Eksklusif pada ibu bekerja.

Peraturan yang ada terkait dengan cuti melahirkan adalah pekerja perempuan berhak mendapatkan tiga bulan selama proses melahirkan. Oleh karena itu, ibu bekerja harus mengeluarkan ASI ketika sedang berada di tempat bekerja yang dapat dipergunakan oleh anaknya di rumah. Ketika ibu menyusui tidak bersama dengan anaknya, maka perlu memerah ASI untuk menjaga pasokan ASI dan mencegah komplikasi yang biasa terjadi 
seperti pembengkakan payudara, kebocoran ASI, dan tersumbatnya payudara.

Tempat bekerja diwajibkan menyediakan ruang laktasi sesuai dengan amanah PP No 33 Tahun 2012 tentang ASI Eksklusif yang ditujukan bagi ibu bekerja yang masih menyusui anaknya sehingga ibu bekerja dapat memerah ASI dengan cara dipompa menggunakan alat khusus maupun secara manual atau dengan tangan. Masih rendahnya target angka capaian pemberian ASI eksklusif membuat instansi yang berwenang perlu membuat peraturan yang dapat mendukung ibu bekerja supaya tetap dapat memberikan ASI kepada anaknya.

Berikut adalah beberapa kebijakan dalam lingkup internasional maupun nasional yangmengupayakan hak ibu bekerja untuk memberikan ASI kepada anaknya dapat terakomodasi antara lain :

1) ILO, melalui Konvensi Internasional No. 183 Tahun 2000 Tentang Konvensi Perlindungan Maternitas. Pasal 10 ayat 1 dan 2.

2) UU Ketenaga kerjaan Tahun 2003 Pasal 83 menyatakan bahwa pekerja/buruh perempuan yang anaknya masih menyusu harus diberi kesempatan sepatutnya untuk menyusui anaknya jika hal itu harus dilakukan selama waktu kerja.

3) Peraturan bersama tiga menteri: Menteri Negara Pemberdayaan
Perempuan, Menteri Tenaga Kerja dan Transmigrasi, dan Menteri Kesehatan Nomor

48/MEN.PP/XII/2008,

27/MEN/XII/2008, DAN 1177/MENKES/PB/XII/2008

Tahun2008 Tentang Peningkatan Pemberian Air Susu Ibu Selama Waktu Kerja di Tempat Bekerja.

4) PP No 33 Tahun 2012 Tentang ASI Eksklusif, pasal 30, 31, 34, 35, 36, 37 Peraturan-peraturan di atas menunjukkan adanya keleluasaan bagi ibu bekerja untuk dapat menyusui sehingga anaknya memperoleh ASI eksklusif. Selain itu, adanya peraturan tersebut juga diharapkan semakin banyaknya cakupan ASI eksklusif sehingga target capaian ASI eksklusif sebesar 80 persen dapat tercapai. Akan tetapi, realita yang terjadi di lapangan tidak sesuai dengan yang terdapat dalam peraturan. Tidak semua tempat bekerja mau dan menyediakan ruang menyusui untuk para pegawainya, bahkan kurangnya dukungan dari lingkungan sosial.

Dalam usaha memberikan ASI eksklusif, ibu bekerja menghadapi halangan dan rintangan yang tidak kecil. Akan tetapi, meskipun dengan segala keterbatasan yang dimiliki, ibu bekerja harus tetap bisa memerah ASI dengan fasilitas minimal dan tekanan maksimal. Meskipun terdapat peraturan yang mewajibkan

tempat 
bekerja menyediakan ruang menyusui untuk pegawainya dan perlunya dukungan dari masyarakat, pada kenyataannya masih banyak tempat bekerja yang tidak memiliki ruang menyusui. Hal ini dapat diketahui dari survei yang dilakukan oleh AIMI dengan Save the Children di Aceh, Jawa Barat, dan Nusa Tenggara Timur (NTT) menunjukkan dari 37 kantor pemerintah yang diteliti hanya empat kantor atau 10,81 persen yang sudah mempunyai fasilitas ruangan menyusui khusus. Tak berbeda jauh dengan kantor pemerintah, di kantor swasta juga mengalami hal yang sama, hanya dua kantor dari 18 kantor yang disurvei memiliki ruang menyusui.

Hasil penelitian juga sejalan dengan penelitian Oktora yang menyimpulkan bahwa kegagalan pemberian ASI eksklusif bagi ibu bekerja ini dapat dikarenakan beberapa faktor. Salah satu faktor yaitu tidak adanya kebijakan khusus dari tempat kerja terhadap ibu menyusui, jam kerja yang tidak sesuai dengan peraturan jam kerja yang telah ditetapkan, tidak adanya tempat untuk memompa ASI bagi karyawan yang menyusui, serta kurangnya dukungan dari pimpinan perusahaan dalam memberikan toleransi kepada wanita menyusui.

Hasil penelitian ini sesuai dengan penelitian yang dilakukan oleh Nurjanah yang menyimpulkan bahwa fasilitas, waktu, dan dukungan dari atasan yang memungkinkan ibu untuk memberikan ASI masih belum memadai.

Minimnya waktu istirahat dan tidak adanya fasilitas penyimpanan ASI misalnya kulkas, merupakan faktor-faktor yang menyebabkan dukungan tempat kerja terhadap pemberian ASI menjadi rendah. Hal tersebut sebagaimana dikemukakan oleh Khrist (2011) bahwa bagi ibu yang bekerja kesulitan untuk menyusui bayinya secara eksklusif dikarenakan lebih banyak waktu di luar rumah dan tidak adanya fasilitas khusus untuk memberikan ASI di tempat bekerja, sehingga mereka lebih memilih memberikan susu formula sebagai pengganti ASI.

Salah satu faktor pemungkin yang dapat mempengaruhi keberhasilan pemberian ASI eksklusif terutama pada ibu yang bekerja adalah hak menyusui di tempat kerja dan ketersediaan sarana memerah dan menyimpan ASI seperti ruang menyusui, alat pompa, botol tempat menyimpan ASI dan lemari pendingin. Hal ini amatlah penting mengingat tidak semua ibu yang bekerja dapat membawa anaknya ke tempat kerja dan mereka pun memiliki lebih sedikit waktu untuk menyusui anaknya di rumah. Oleh sebab itu, untuk tetap memenuhi kebutuhan bayi akan ASI, ibu yang bekerja seharusnya mampu menyimpan ASI-nya selama bekerja, baik disimpan di rumah ataupun 
di tempat kerja. Akan tetapi, tidak semua pekerja perempuan dapat melakukan hal tersebut secara leluasa didalam pabrik tempat mereka bekerja. Seringkali mereka dibatasi oleh peraturan yang diterapkan oleh perusahaan serta ketidaktersediaannya ruang memerah dan sarana menyimpan ASI seperti botol ASI, termos pendingin dan kulkas.

\section{KESIMPULAN}

Berdasarkan hasil penelitian didapatkan sebagian besar karakteristik umur berusia 20 - 35 tahun sebanyak $94,1 \%$, pendidikan tinggi sebanyak $73,5 \%$, pekerjaan karyawan swasta termasuk pegawai bank dan SPG sebanyak $50 \%$, responden mayoritas telah melahirkan anak >2 kali sebanyak 50\% dan memiliki rata-rata jam kerja selama 7 -8 jam.

Berdasarkan hasil uji Chi-Square didapatkan adanya pengaruh yang signifikan antara dukungan suami dan atasan terhadap keberhasilan pemberian ASI ekslusif. Dimana ibu-ibu yang mendapatkan dukungan suami dirumah dan dukungan atasan dikantor berpeluang untuk bisa berhasil menyusui bayinya ekslusif hingga 6 bulan.

\section{DAFTAR PUSTAKA}

Haile D, Belachew T, Berhanu G, Setegn T, Biadgilign S. Stability of infant and child feeding index over time and its association with nutritional status of HIV exposed infants in sidama zone, southern Ethiopia: a longitudinal study. Early Hum Dev. 2014;90(12):815-20.

Kuzma J. Knowledge, attitude and practice related to infant feeding among

women in rural Papua New Guinea: a descriptive, mixed method study. Int Breastfeed J. 2013;8:16.

Kementerian Kesehatan. 2012. Peraturan Pemerintah RI Nomor 33 Tahun 2012 Tentang Pemberian Air Susu Ibu Eksklusif. Jakarta: Kemenkes RI.

Pinkney K. The practice and attitudes of gypsy and traveller women towards early infant feeding. Community Pract. 2012;85(7):26-9.

Muluye D, Woldeyohannes D, Gizachew M, Tiruneh M. Infant feeding practice and associated factors of HIV positive mothers attending prevention of mother to child transmission and antiretroviral therapy clinics in Gondar town health institutions, northwest Ethiopia. BMC Public Health. 2012;12:240.

Kadir, Nurhira Abdul. 2014. Menelusuri Akar Masalah Rendahnya Pemberian ASI Eksklusif Di Indonesia. http://www.uinalauddin.ac.id/202014-2.pdf (Diakses pada tanggal 13 Oktober 2015).

Ari, D.R.K \& Adriani, Feyriska Rahma. 2015. Membesarkan Anak Hebat Dengan ASI. Yogyakarta: Citra Media Pustaka.

Permatasari, Putri. 2015. Gambaran data demografi pemberian ASI pada wanita pekerja swasta di Desa Jetis Wilayah Kerja Puskesmas Baki 1 Kabupaten Sukoharjo. Skripsi. Progran Studi Keperawatan Fakultas Ilmu Kesehatan Universitas Muhamadiah Surakarta. 
United Nations Children's Fund (UNICEF). Improving exclusive breastfeeding practices: communication for development in infant and young child feeding programmes. 2012.

Ryan AS, Hay WW. Challenges of infant nutrition research: a commentary. Nutr J. 2016;15:42.

Dinas Kesehatan Provinsi Nusa Tenggara Barat. 2014. Cakupan ASI Eksklusif Tahun 2014.

Dinas Kesehatan Kota Mataram. 2014. Cakupan ASI Eksklusif Tahun 2014.

Roesli, Oetami. ASI Eksklusif. Edisi II, Trubus Agriwidya ; Jakarta. 2004.

Roesli, Oetami. Petunjuk Praktis Menyusui, Trubus Agriwidya ; Jakarta. 2005.

Eidelman AI. Breastfeeding: beyond nutrition, breastfeeding support: beyond biology. Breastfeeding medicine. Breastfeed Med. 2016;11:1.

A, Quan le N, Do M, Marsh DR, Dearden K. Pachon H, Schroeder DG, Lang TT. Work outside the home is the primary barrier to exclusive breastfeeding in rural Vietnam: insights from mothers who exclusively breastfed and worked. Food and Nutrition Bulletin 2002; 23 Suppl 4:101-8.

Riordan J. Breastfeeding and Human Lactation. Boston: Jones and Bartlett Publishers; 2010.

Glenn JS. Knowledge, perceptions, and attitudes of managers, coworkers, and employed breastfeeding mothers. American Association of Occupational Health Nurses Journal 2008; 56(10):423-31

Hami, Ratu Ummu. 2014. Hubungan Dukungan Suami Terhadap Keberhasilan Pemberian Asi Eksklusif Pada Ibu Primipara di Wilayah Kerja Puskesmas Pisangan. Skripsi Program Studi
Ilmu Keperawatan Fakultas Kedokteran dan Ilmu Kesehatan. Universitas Islam Negeri Sarif Hidayatullah. Jakarta.

Rosyadi, Dina Wahyu. 2016. Hubungan Antara Pengetahuan Ibu Bekerja, Jam Kerja Ibu dan Dukungan Tempat Kerja Dengan Keberhasilan Pemberian Asi Eksklusif di Wilayah Kerja Puskesmas Banyudono I. Skripsi Program Studi Kesehatan Masyarakat Fakultas Ilmu Kesehatan. Universitas Muhammadiyah Surakarta.

Oktora, Rasti. (2013). Gambaran Pemberian Asi Eksklusif Pada Ibu Bekerja Di Desa Serua Indah, Kecamatan Jombang, Tangerang Selatan. Jurnal Kesehatan Reproduksi, 4, 30-40.

Nurjanah. (2008). Implementasi Pasal Undang-undang No 13 Tahun 2003 Tentang Hak Menyusui Pekerja Perempuan Selama Bekerja. Jurnal Promosi Kesehatan Indonesia, 3, 1.

Khrist, G, Josefa. 2011. Faktor-faktor yang Mempengaruhi Perilaku Pemberian ASI Eksklusif pada Ibu (Studi Kasus di Wilayah Kerja Puskesmas Manyaran, Kecamatan Semarang Barat. Artikel Penelitian. Semarang: Program Pendidikan Sarjana Kedokteran. Fakultas Kedokteran. Universitas Diponegoro.

Rizkianti, Anissa. Prasodjo, Rachmalina. Novianti. Saptarini, Ika. Analisis Faktor Keberhasilan Praktik Pemberian Asi Eksklusif Di Tempat Kerja Pada Buruh Industri Tekstil di Jakarta. Bul. Penelit. Kesehat, Vol. 42, No. 4, Desember 2014: 237-248. 